\title{
Erratum to: Plausibility Judgments of Atypical Symptoms Across Cultures: an Explorative Study Among Western and Non-Western Experts
}

\author{
Irena Boskovic ${ }^{1,2}$ - Douwe van der Heide ${ }^{3} \cdot$ Lorraine Hope $^{2}$ - Harald Merckelbach ${ }^{1}$. \\ Marko Jelicic ${ }^{1}$
}

Published online: 16 August 2017

(C) Springer Science+Business Media, LLC 2017

Erratum to: Psychol. Inj. and Law

DOI 10.1007/s12207-017-9294-6

Correction of mistake in the original version of this paper, "Plausibility Judgments of Atypical Symptoms Across Cultures: an Explorative Study Among Western and NonWestern Experts", the sentence "We conducted a 2 (Western vs non-Western) $\times 3$ (SIMS versus DES-T-versus BSI-18 items) analysis of variance (ANOVA)." should read "We conducted a multivariate analysis of variance (MANOVA), where dependent variables were the plausibility scores on SIMS, DES-T, and BSI-18, and the independent variable was culture background of professionals (Western vs non-Western)."
The footnote "We also ran this ANOVA with working experience as a covariate, and none of the results reached significance: $\lambda=.97, F(3.89)=.98, p=.40$, SIMS $F(1.90)=2.71$, $p=.11, \mathrm{DES}-\mathrm{T} F(1.90)=2.01, p=.16$; BSI-18 $F(1.90)=.30$, $p=.60$." should read "We also ran this MANOVA with working experience as a covariate, and none of the results reached significance: $\lambda=.97, F(3.89)=.98, p=.40$, SIMS $F(1.90)=2.71, p=.11$, DES-T $F(1.90)=2.01, p=.16$; BSI-18 $F(1.90)=.30, p=.60 . ”$

The online version of the original article can be found at http://dx.doi.org/ 10.1007/s12207-017-9294-6

Irena Boskovic

irena.boskovic@maastrichtuniversity.nl

1 Forensic Psychology Section, Maastricht University, P.O. Box 616, 6200 MD Maastricht, The Netherlands

2 University of Portsmouth, Portsmouth, UK

3 GGZ Centraal, Ermelo, The Netherlands 